\title{
Effects of resistance plus aerobic training on body composition and metabolic markers in older breast cancer survivors undergoing aromatase inhibitor therapy ${ }^{\text {in }}$
}

\author{
Thais R.S. de Paulo ${ }^{\mathrm{a}, \mathrm{b}, *}$, Kerri M. Winters-Stone ${ }^{\mathrm{c}}$, Juliana Viezel ${ }^{\mathrm{b}}$, Fabricio E. Rossi ${ }^{\mathrm{b}, \mathrm{d}}$, \\ Regina R. Simões ${ }^{\mathrm{e}}$, Giuliano Tosello ${ }^{\mathrm{f}}$, Ismael F. Freitas Junior ${ }^{\mathrm{b}}$ \\ ${ }^{\text {a }}$ Department of Physical Education, Federal University of Rio Grande do Norte (UFRN), Natal, RN, Brazil \\ b Post Graduation Program in Motricity Science, São Paulo State University (UNESP), School Technology and Science, Presidente Prudente, SP, Brazil \\ ${ }^{\mathrm{c}}$ School of Nursing, Knight Cancer Institute, Oregon Health \& Science University, Portland, OR, USA \\ d Federal University of Piauí, UFPI, Teresina, Brazil \\ e Federal University of Triângulo Mineiro, UFTM, Brazil \\ ${ }^{f}$ Federal University of Sao Paulo, USP, Sao Paulo, Brazil
}

\section{A R T I C L E I N F O}

Section Editor: Emanuele Marzetti

Keywords:

Physical activity

Cancer

Exercise training

Body composition

Metabolic health

\begin{abstract}
A B S T R A C T
Objective: To evaluate the effects of combined aerobic + resistance training on body composition and metabolic markers in older breast cancer survivors undergoing aromatase inhibitor therapy.

Methods: Older breast cancer survivors were randomized to an exercise [resistance + aerobic training]: $\mathrm{n}=18$, or placebo control group: $\mathrm{n}=18$. Body composition (measured by DXA) and blood markers of lipid and glucose were measured at baseline, and at 12,24 , and 36 weeks. The exercise group performed 40 min of resistance exercises on machines followed by $30 \mathrm{~min}$ of aerobic training on a treadmill, three times per week. Separate 2 (group) $\times 4$ (time) repeated-measure ANOVAs were used to compare groups over time.

Results: Significant group $\times$ time interactions were found for total and trunk fat mass $(\mathrm{p}<0.001$ and $\mathrm{p}=0.001)$ and $\%$ body fat $(\mathrm{p}<0.001)$, where women in the exercise group lost fat compared to slight gains among women in the stretching control group. There were no significant differences between groups for lean mass, hip or spine BMD, metabolic markers, or CRP.

Conclusion: Our aerobic + resistance exercise program prevented fat gain, but may not have been sufficient to improve metabolic or bone health markers in older breast cancer survivors undergoing aromatase inhibitor therapy.
\end{abstract}

\section{Introduction}

Cancer is one of the major public health problems and leading causes of death in the world (National Center for Health Statistics, 2016). With the growth in the world population, the number of new cases is expected to increase considerably, reaching 20.3 million by 2030 (Ferlay et al., 2010). Among all types of cancers, breast cancer is the most common among women (International Agency for Research on Cancer, 2012). According to the National Cancer Institute, in 2017, it is estimated that over 57,960 new cases of breast cancer will occur in Brazilian women (Instituto Nacional do Câncer (INCA), 2016).

In postmenopausal women, $80 \%$ of breast cancer cases are hormone receptor positive (Bardia et al., 2012) and aromatase inhibitor therapy
(AI) is typically prescribed as standard treatment, which increases survival rates upwards of $40 \%$ compared to tamoxifen (Riemsma et al., 2010). However, treatment of breast cancer with aromatase inhibitor therapy can produce alterations in body composition, such as increases in body fat mass as well as decreases in lean body mass and bone mineral density (Napoli et al., 2015; Battisti et al., 2014; Van Londen et al., 2011) and, these alterations can increase the risk of fractures, osteoporosis, and chronic diseases (Akyol et al., 2016; Saarto et al., 2008). In addition, the side effects of AI also include loss of bone mineral density of $2.6 \%$ per year and symptoms of arthralgia and myalgia (Limburg, 2007; Peppone et al., 2010). AI decreases circulating estrogens and thus may also may weaken estrogen-mediated protective effects on the cardiovascular system among women on AI (Amir et al.,

\footnotetext{
¿ Declarations of interest: none.

* Corresponding author at: Rua Roberto Simonsen, 305, Zip Code: 19060-900 Presidente Prudente, SP, Brazil.

E-mail address: Thais.reis.silva@hotmail.com (T.R.S. de Paulo).
} 
2011; Foglietta et al., 2017).

A non-pharmacological alternative to reverse or attenuate the side effects of breast cancer treatment on body composition is exercise training. Several studies have shown that exercise is effective for improving body composition (increased lean body mass, decreased fat body mass, and body mineral density at the spine, hip, and whole body), inflammatory and metabolic blood markers, physical fitness, and quality of life of breast cancer survivors (Battaglini et al., 2014; DieliConwright and Orozco, 2015; Almstedt et al., 2016). Thomas et al. (2016) demonstrated an association between 12 months of combined exercise (twice-weekly supervised resistance training program and 150 min of moderate-intensity aerobic exercise at home) with a decrease in percentage body fat and an increase in lean body mass in postmenopausal breast cancer survivors taking AI.

However, there are few studies including exercise programs which combine aerobic and resistance training for women undergoing treatment for breast cancer with aromatase inhibitor therapy. Furthermore, the long term benefits of combining resistance and aerobic training in breast cancer survivors on AI are not clear, and more studies are needed with this population, focusing on responses of combined exercise on body composition and metabolic markers. Thus, the aim of this study was to evaluate the effects of combined aerobic + resistance training on body composition and metabolic markers in older breast cancer survivors undergoing aromatase inhibitor therapy.

\section{Methods}

\subsection{Study design}

We conducted a 36 week single-blind, parallel group randomized controlled trial from March 2015 to July 2016 in a city in the southeastern region of Brazil (ClinicalTrials.gov NCT02804308). Women were randomized to a resistance + aerobic training group or a low-intensity stretching control group. All testing and exercise training took place at the Sao Paulo State University-Campus of Presidente Prudente, physical education department. This study was approved by the Research Ethics Committee of the Sao Paulo State University (Protocol number 6727715.1.0000.5402/2015).

\subsection{Subjects}

According to the Medical records in the Oncology Department of the Regional Hospital in Presidente Prudente, São Paulo state, Brazil, a total of 348 registered breast cancer survivors were found, including all types of treatment for cancer. In the present study, only postmenopausal breast cancer survivors undergoing aromatase inhibitor therapy were recruited, totaling 124 women invited to participate in the study. The study inclusion criteria were the following: current use of AI, diagnosis of stage $0-3$ a breast cancer, aged between 50 and 80 years, no participation in supervised exercise in the previous six months, no musculoskeletal injuries, clearance from a physician to participate in physical training, and living in the city of Presidente Prudente/Sao Paulo.

To calculate the sample size, we performed a power analysis based on observations from a previous study that verified a difference in bone mineral density $\left(\mathrm{g} / \mathrm{cm}^{2}\right)$ at the lumbar spine of $0.013 \mathrm{~kg}$ and standard deviation of 0.011 after 12 months of exercise training in postmenopausal breast cancer survivors (Saarto et al., 2012). Using a power (1-type II error) of 0.80 and a type I error of 0.05 , according to PS software (see 3.1.2, Dupont and Plummer, http://biostat.mc.vanderbilt. edu/wiki/Main/PowerSampleSize), it was estimated that we would need 12 subjects per group. Considering a dropout rate of $20 \%$, we over-recruited the number of subjects to recruit a target sample of $\mathrm{n}=14$.

A total of 36 women were included in this study: 18 women in the exercise group (EX) and 18 in the stretching control group (CG). The participant flow is outlined in Fig. 1.

\subsection{Study interventions}

\subsubsection{Combined training group}

2.3.1.1. Aerobic and strength assessment and training protocol. Maximal muscle strength was evaluated by a predicted one repetition maximum test. The submaximal load of each individual was established and the maximum of 10-12 repetitions was considered in this study. The participants performed the test in bench press and leg press exercises. Predicted 1-RM was determined using a standard equation (Adams, 1994). The protocol used to predict maximum aerobic capacity was a single-stage submaximal treadmill Walking Test according to Ebbeling et al. (1991). Each participant performed a 4 minute warm up at a speed that elevated the HR to between $50 \%$ and $70 \%$ of estimated HRmax (HRmax $=220$-age). Next, the inclination of the treadmill was adjusted to $5 \%$ and maintained at the same speed for $4 \mathrm{~min}$. The value of HRmax was recorded every $30 \mathrm{~s}$ during the final $2 \mathrm{~min}$ and values could not differ more than $5 \mathrm{bpm}$ in each stage. Maximum oxygen uptake $\left(\mathrm{VO}_{2 \max }\right)$ was predicted using standard equations.

Participants in the exercise group participated in the combined aerobic + resistance program (Paulo et al., 2018) three times per week for 36 weeks for approximately $100 \mathrm{~min}$ per session. All sessions were supervised by physical education professionals and were performed in a gym at Sao Paulo State University, Presidente Prudente campus, physical education department. Each daily session began with a 5 minute warm up and ended with 10 minute cool-down. After the warm-up, resistance training was performed, including exercises for the main muscle groups on weight machines: seated cable row, bench press, leg extension, leg press, and leg curl, as well as bridge, abdominal, and standard plank exercises. The training volume of workload, number of sets, and number of repetitions of each resistance training series consisted of four progressive stages, as shown in Table 1. Next, the aerobic training was performed on a treadmill (Movement, LX-160, Fitness Equipment, Pompeia, Sao Paulo, Brazil) for $30 \mathrm{~min}$ with the intensity based on estimated maximum heart rate (HR) within the target training zone and monitored via heart rate monitors (model S810i; Polar Electro, Kempele, Finland). The aerobic protocol consisted of four progressive stages, also described in Table 1 .

Participants in the exercise group were invited to attend $1.5 \mathrm{~h}$ health education lectures once per month. The topics discussed were related to breast cancer, health promotion, quality of life, physical activity, wellbeing, and mental health.

\subsubsection{Stretching control group}

The control group was invited to participate in stretching and relaxation exercises, 2 times per week, with 45 minute sessions, for 36 weeks. Each exercise lasted 10-15 s, in the seated or lying position, and selected exercises minimized muscular force so that little stimulus was applied to the musculoskeletal system. The main goal of the stretching and relaxation exercises was to provide similar attention to the control group and minimize drop out and contamination.

\subsection{Measures}

\subsubsection{Self-reported demographics and health status}

Characterization of the sample was performed through a sociodemographic self-reported questionnaire and clinical information; including demographic data, breast cancer stage, treatment type, use of medication, and health history.

\subsubsection{Anthropometry, body composition, and dietary intake}

To calculate the body mass index - BMI $\left(\mathrm{kg} / \mathrm{m}^{2}\right)$ - weight was assessed on a mechanical scale (Fillizola) to the nearest $0.1 \mathrm{~kg}$ and height was measured with the use of a fixed stadiometer (Sanny) to the nearest $0.1 \mathrm{~cm}$. Body composition (total fat, trunk fat, and lean mass $(\mathrm{kg})$, percentage of fat mass (\%), and spine and hip bone mineral density BMD $\left(\mathrm{g} / \mathrm{cm}^{2}\right)$ ) were estimated by Dual-Energy X-ray Absorptiometry 


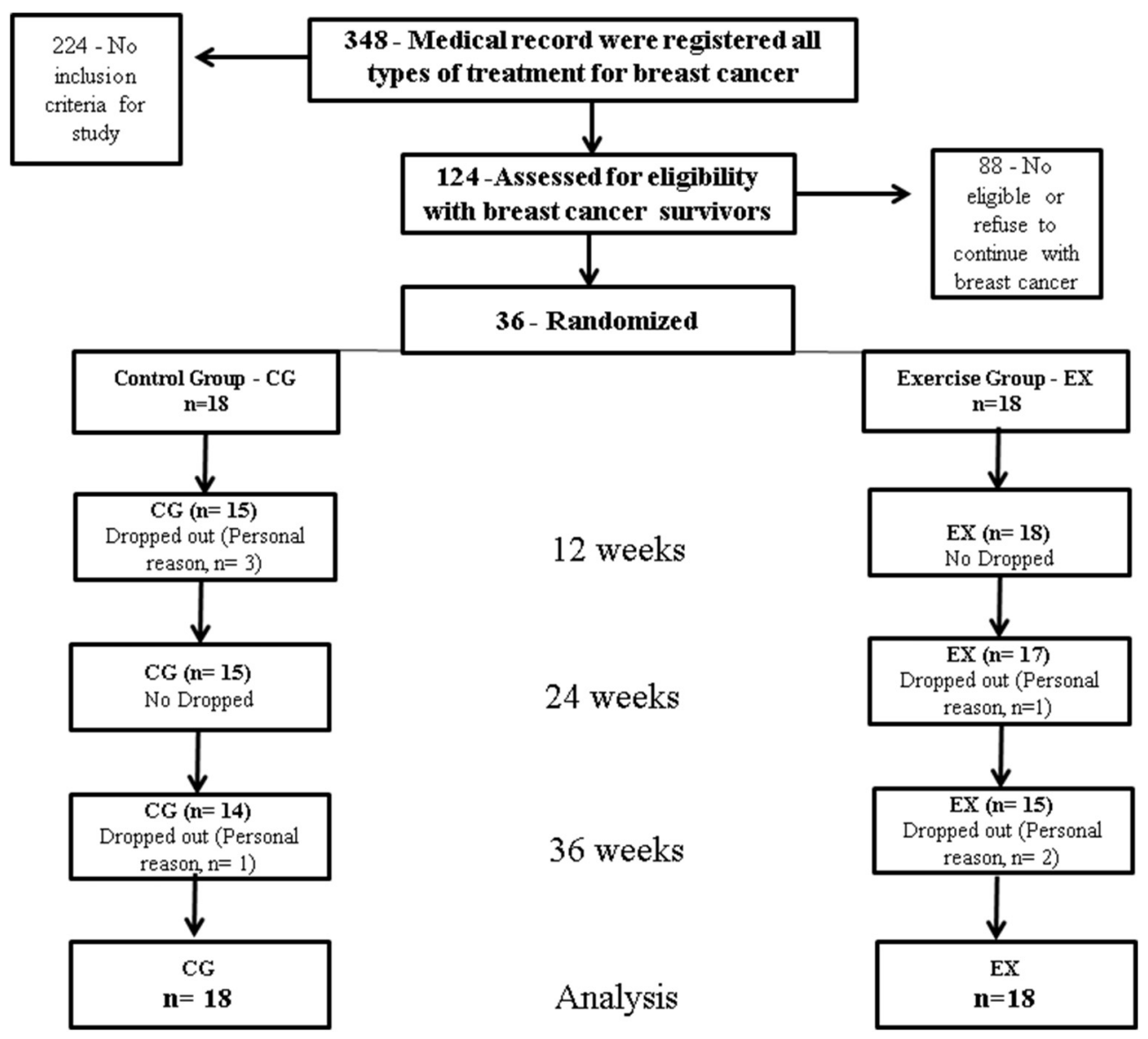

Fig. 1. Participant flow from recruitment to analysis.

Table 1

Planned progression of resistance and aerobic training over 36 weeks. ${ }^{a}$

\begin{tabular}{|c|c|c|c|c|c|c|c|c|}
\hline \multirow[t]{2}{*}{ Weeks } & \multicolumn{5}{|c|}{ Resistance training } & \multicolumn{3}{|l|}{ Aerobic training } \\
\hline & Stage & Intensity & Sets & Repetition & Interval between sets (s) & Stage & Time (min) & Intensity \\
\hline $1-2$ nd & Familiarization & Minimal loads & 1 & 20 & None & Familiarization & 20 & 50-60\% HRmax \\
\hline 3-10th & Stage 1 & $55 \%$ 1-RM & $2-3$ & $15-20$ & $60-90$ & Stage 1 & 30 & 60-65\% HRmax \\
\hline 11-18th & Stage 2 & $60 \% 1-\mathrm{RM}$ & 3 & $12-15$ & $60-90$ & Stage 2 & 30 & $65-70 \%$ HRmax \\
\hline 19-28th & Stage 3 & $65-70 \% 1-\mathrm{RM}$ & 3 & $10-12$ & $60-90$ & Stage 3 & 30 & 70-75\% HRmax \\
\hline 29-36th & Stage 4 & $75 \% 1-\mathrm{RM}$ & 3 & $8-10$ & $60-90$ & Stage 4 & 30 & 75-80\% HRmax \\
\hline
\end{tabular}

${ }^{\text {a }}$ Intensity for resistance exercises set as a \% 1-Repetition Maximum (\% 1-RM) and aerobic progression was by the maximum heart rate (\% HRmax).

(DXA [Lunar brand, DPX-MD, software 4.7]).

Twenty-four hour daily dietary records were conducted via threeday food diaries that consisted of two weekdays (Monday and Wednesday or Tuesday and Thursday) and one weekend day. Total intake and macronutrient distribution for the three days were then averaged and represented at baseline and after the program. Participants were instructed by a nutritionist as to how to complete the dietary questionnaires. Questionnaires were analyzed by the same nutritionist using the software NutWin version 1.5 (Programa de Apoio à Nutrição, Universidade Federal de São Paulo, São Paulo, Brazil, 2002).

\subsubsection{Inflammation and metabolic blood markers}

Blood samples were collected and processed in a specialized laboratory, after $12 \mathrm{~h}$ of fasting, for all variables at baseline, and at 12 , 24 , and 36 weeks. The plasma samples were stored at $-80^{\circ} \mathrm{C}$ until assayed and the collection was carried out in vacuum tubes with a gel separator without anticoagulant; after collection, the blood was centrifuged for $10 \mathrm{~min}$ at $3000 \mathrm{rpm}$ to separate the serum from other components of the blood, and the serum was used for analysis. The metabolic variables of interest for this study were serum levels of total cholesterol (mg/dl), high-density lipoprotein - HDL (mg/dl), low-density lipoprotein - LDL (mg/dl), and triglycerides (mg/dl), analyzed by an automatic biochemical analyzer RAXT (Technicon, USA), and glucose $(\mathrm{mg} / \mathrm{dl})$ measured by a colorimetric enzymatic kit processed in an Autohumalyzer unit (Human and Jones, 2004). C-reactive protein - CRP $(\mathrm{mg} / \mathrm{dl})$ was measured using an ELISA enzymatic kit: Immulite 2000 analyzer (Siemens Healthcare Diagnostics) (Friedenreich et al., 2012). Biochemical markers of bone remodeling (formation and resorption) have the potential to provide initial feedback on the short-term effects of an intervention on bone metabolism. In the present study, serum osteocalcin $(\mathrm{ng} / \mathrm{ml})$ and the carboxy-terminal telopeptide of type I collagen CTX (ng/ml) were measured by Serum CrossLaps Assay (Kanis et al., 2013). 
Table 2

Baseline sociodemographic and clinical characteristics of breast cancer survivors.

\begin{tabular}{|c|c|c|c|}
\hline Variables & $\begin{array}{l}\text { Control group } \\
(\mathrm{n}=18)\end{array}$ & $\begin{array}{l}\text { Exercise group } \\
(\mathrm{n}=18\end{array}$ & $\mathrm{p}$ value \\
\hline Age & $66.6 \pm 9.6$ & $63.2 \pm 7.1$ & 0.23 \\
\hline Weight (kg) & $31.5 \pm 6.2$ & $28.9 \pm 5.2$ & 0.19 \\
\hline Height $(\mathrm{cm})$ & $153.1 \pm 4.5$ & $154.1 \pm 6.7$ & 0.33 \\
\hline BMI & $72.3 \pm 13.1$ & $66.9 \pm 10.3$ & 0.18 \\
\hline \multicolumn{4}{|l|}{ Level of schooling (\%) } \\
\hline$<$ High school & 50 & 47 & \\
\hline High school & 27.8 & 23.6 & 0.73 \\
\hline$>$ High school & 22.2 & 29.4 & \\
\hline \multicolumn{4}{|l|}{ Marital status (\%) } \\
\hline Single & 5.6 & 11.1 & \\
\hline Married & 55.6 & 61.1 & 0.53 \\
\hline Divorced & 0 & 5.6 & \\
\hline Widowed & 38.9 & 22.2 & \\
\hline \multicolumn{4}{|l|}{ Occupation (\%) } \\
\hline Homemaker & 50 & 55.6 & \\
\hline Employed & 16.7 & 5.6 & 0.27 \\
\hline Retired & 33.3 & 38.9 & \\
\hline \multicolumn{4}{|l|}{ Children (\%) } \\
\hline No & 5.6 & 5.6 & 0.82 \\
\hline Yes & 94.4 & 94.4 & \\
\hline \multicolumn{4}{|l|}{ Cancer stage (\%) } \\
\hline I & 58.8 & 50 & \\
\hline II & 23.6 & 33.3 & 0.74 \\
\hline III & 17.6 & 17.6 & \\
\hline \multicolumn{4}{|l|}{ Type of surgery (\%) } \\
\hline Partial mastectomy & 58.8 & 47.4 & 0.73 \\
\hline Total mastectomy & 41.2 & 52.6 & \\
\hline \multicolumn{4}{|l|}{$\begin{array}{l}\text { General treatment received } \\
\quad(\%)\end{array}$} \\
\hline Chemotherapy & 69.3 & 66.6 & 0.31 \\
\hline Radiotherapy & 75.2 & 77.8 & 0.10 \\
\hline $\begin{array}{l}\text { Chemotherapy and } \\
\text { radiotherapy }\end{array}$ & 38.9 & 50 & 0.50 \\
\hline Time of use of AI (months) & $17.9 \pm 11.2$ & $19.3 \pm 8.3$ & 0.66 \\
\hline \multicolumn{4}{|l|}{ Number of diseases (\%) } \\
\hline 2 diseases & 16.7 & 27.8 & 0.53 \\
\hline$>2$ diseases & 83.3 & 72.8 & \\
\hline \multicolumn{4}{|l|}{$\begin{array}{l}\text { Medicine used in a } \\
\text { continuous manner }\end{array}$} \\
\hline 2 medicine & 24.8 & 22.2 & 0.97 \\
\hline$>2$ medicine & 75.2 & 77.8 & \\
\hline
\end{tabular}

Numerical variables expressed as mean and standard deviation.

Categorical variables expressed as \%. No statistically significant baseline differences between groups.

\subsection{Statistical analysis}

To test the normality of the sample, the Kolmogorov-Smirnov normality test was performed and the sample characterization analysis was carried out using the Student's $t$-test. We computed means and standard deviations for continuous variables, and frequencies and percentages for categorical variables. In the present study, the intent-to-treat (ITT) analysis was performed; this approach uses the most rigorous information and estimates data handling throughout the study,
Table 4

Baseline body composition and blood markers characteristics of breast cancer survivors.

\begin{tabular}{|c|c|c|c|}
\hline \multirow[t]{2}{*}{ Variables } & $\begin{array}{l}\text { Control group } \\
(\mathrm{n}=18)\end{array}$ & $\begin{array}{l}\text { Exercise group } \\
(\mathrm{n}=18)\end{array}$ & \multirow[t]{2}{*}{$\mathrm{p}$ value } \\
\hline & $\begin{array}{l}\text { Baseline } \\
\text { Mean } \pm \text { SD }\end{array}$ & $\begin{array}{l}\text { Baseline } \\
\text { Mean } \pm \text { SD }\end{array}$ & \\
\hline Height $(\mathrm{cm})$ & $153.2 \pm 9.6$ & $154.2 \pm 6.8$ & 0.61 \\
\hline Total mass $(\mathrm{kg})$ & $72.3 \pm 13.1$ & $66.9 \pm 10.3$ & 0.18 \\
\hline BMI $\left(\mathrm{kg} / \mathrm{m}^{2}\right)$ & $31.5 \pm 6.3$ & $28.9 \pm 5.2$ & 0.19 \\
\hline Total lean mass (kg) & $36.2 \pm 5.1$ & $33.7 \pm 3.9$ & 0.07 \\
\hline $\begin{array}{l}\text { Appendicular lean mass } \\
\quad(\mathrm{kg})\end{array}$ & $16.1 \pm 2.4$ & $15.0 \pm 1.5$ & 0.23 \\
\hline Total fat mass $(\mathrm{kg})$ & $33.8 \pm 9.2$ & $31.1 \pm 8.0$ & 0.93 \\
\hline Total fat mass (\%) & $46.2 \pm 5.1$ & $45.8 \pm 5.8$ & 0.34 \\
\hline Trunk fat mass $(\mathrm{kg})$ & $17.6 \pm 4.6$ & $17.1 \pm 4.3$ & 0.70 \\
\hline Spine BMD $\left(\mathrm{g} / \mathrm{cm}^{2}\right)$ & $1.1 \pm 0.1$ & $1.0 \pm 0.1$ & 0.27 \\
\hline Hip BMD $\left(\mathrm{g} / \mathrm{cm}^{2}\right)$ & $0.9 \pm 0.1$ & $0.9 \pm 0.1$ & 0.32 \\
\hline $\begin{array}{l}\text { Trochanter BMD }(\mathrm{g} / \\
\left.\mathrm{cm}^{2}\right)\end{array}$ & $0.9 \pm 0.1$ & $0.8 \pm 0.1$ & 0.21 \\
\hline Cholesterol (mg/dl) & $207 \pm 41$ & $219 \pm 41$ & 0.64 \\
\hline $\mathrm{HDL}(\mathrm{mg} / \mathrm{dl})$ & $53 \pm 10$ & $55 \pm 10$ & 0.97 \\
\hline LDL (mg/dl) & $131 \pm 36$ & $135 \pm 37$ & 0.53 \\
\hline triglycerides $(\mathrm{mg} / \mathrm{dl})$ & $136 \pm 41$ & $148 \pm 68$ & 0.10 \\
\hline Glucose $(\mathrm{mg} / \mathrm{dl})$ & $110 \pm 22$ & $107 \pm 24$ & 0.87 \\
\hline $\mathrm{CRP}(\mathrm{mg} / \mathrm{dl})$ & $7 \pm 7$ & $5 \pm 4$ & 0.18 \\
\hline CTX (ng/ml) & $0.40 \pm 0.1$ & $0.46 \pm 0.2$ & 0.37 \\
\hline Osteocalcin (ng/ml) & $17 \pm 5$ & $19 \pm 8$ & 0.81 \\
\hline
\end{tabular}

BMI: body mass index.

BMD: bone mineral density.

performing data imputation for the missed data (Alshurafa et al., 2012). The participants of this study were analyzed, according to their originally assigned group and regardless of lack of data at 12,24 , or 36 weeks, to generate unbiased with parameter estimates, and the group mean for data imputation was used for handling missing data.

To determine the intervention effects on body composition, inflammation, and metabolic blood markers, two-way ANOVA 2 (group) $\times 4$ (time) with repeated measures was used and a $2 \times 2$ (group $\times$ time) repeated measures analysis of variance with the Bonferroni adjustment for multiple comparisons was used to compare dietary intake. If there was a significant group $\times$ time interaction, Bonferroni's post-hoc, with the honest significant difference was conducted. For all measured variables, the estimated sphericity was verified according to Mauchly's W test and the Greenhouse-Geisser correction was used when necessary. In addition, body composition and metabolic profile were controlled for energy intake after the intervention. The significance level for all comparisons was set at $5 \%$. The effect size was considered low, moderate, or high represented by Cohen's d (Cohen, 1988), greater than 0.2, 0.5, and 0.8, respectively. The data were analyzed using the SPSS software (version 24.0).

\section{Results}

On average, women in the exercise group were 63 years old and in

Table 3

Dietary intake and macronutrient distribution of the sample.

\begin{tabular}{|c|c|c|c|c|c|}
\hline \multirow[t]{2}{*}{ Dietary intake } & \multicolumn{2}{|c|}{ Exercise group $(\mathrm{n}=18)$} & \multicolumn{2}{|c|}{ Control group $(\mathrm{n}=18)$} & \multirow[t]{2}{*}{$\mathrm{p}$} \\
\hline & $\begin{array}{l}\text { Baseline } \\
\text { Mean } \pm \text { SD }\end{array}$ & $\begin{array}{l}36 \text { weeks } \\
\text { Mean } \pm S D\end{array}$ & $\begin{array}{l}\text { Baseline } \\
\text { Mean } \pm \text { SD }\end{array}$ & $\begin{array}{l}36 \text { weeks } \\
\text { Mean } \pm S D\end{array}$ & \\
\hline CHO (g) & $309.6 \pm 26.3$ & $286.8 \pm 30.8$ & $314.3 \pm 28.4$ & $297.2 \pm 33.1$ & 0.487 \\
\hline PRO (g) & $155.9 \pm 41.2$ & $168.9 \pm 15.1$ & $153.8 \pm 10.2$ & $162.9 \pm 12.7$ & 0.412 \\
\hline FAT $(g)$ & $84.6 \pm 6.7$ & $85.8 \pm 11.4$ & $83.3 \pm 6.5$ & $87.1 \pm 9.4$ & 0.071 \\
\hline Total intake (kcal) & $2440.8 \pm 150$ & $2431 \pm 114$ & $2433.6 \pm 121$ & $2448 \pm 98$ & 0.237 \\
\hline
\end{tabular}

$\mathrm{CHO}=$ carbohydrate; $\mathrm{PRO}=$ protein $; \mathrm{FAT}=$ lipids. 
the control group 67 years old; the majority of women were homemakers, married, with children, and with at least a high school education. Approximately $52 \%$ of the exercise group (EX) and $41 \%$ of the control group (CON) had undergone total mastectomies and 66\% EX and $69 \%$ CON received chemotherapy. The majority of the women were diagnosed with stage I breast cancer and the average time on AI was 19.3 months in the EX and 17.9 months in the CON. Retention in the EX was $94 \%$ and in the CON $78 \%$. Adherence to the combined training was $83 \%$ of supervised sessions. The two groups did not significantly differ regarding demographics or clinical characteristics at baseline (Table 2). For dietary intake (expressed in kcal) and macronutrient distribution there were no significant differences between groups across time and interaction (Table 3).

Table 4 shows the body composition and inflammatory and metabolic blood markers at baseline. The women in both groups showed high glucose levels, while for cholesterol (total, HDL, LDL, and no $\mathrm{HDL}$ ), the values were above the normal range. Furthermore, when controlled for energy intake after the intervention there were no significant differences in the metabolic variables. BMD and triglycerides were distributed in the normal range in both the EX and CON. There were no statistical differences between groups for any variable at baseline.

Table 5 presents the mean changes in body composition variables at 12,24 , and 36 weeks for both groups. Significant group $\times$ time interactions for total fat mass ( $p>0.001), \%$ fat mass ( $p>0.001)$, and trunk fat mass $(\mathrm{p}=0.001)$ were found. Follow-up analysis showed that the exercise group demonstrated a significant decrease in total fat mass ( $\mathrm{kg}$ and \%) after the training compared with the control group, presenting a reduction of $5.9 \%$ in total fat mass and $3.9 \%$ in fat percentage. The exercise group also demonstrated favorable changes in trunk fat mass at 36 weeks, with a reduction of $5.8 \%$, as opposed to an increase in the control group of $2 \%$. When controlled for energy intake after the intervention, the significant differences for body fat were maintained. No significant group $\times$ time interaction was found for total lean mass or bone mineral density at either skeletal site.

Table 6 shows the results of the comparisons between metabolic and inflammatory markers at baseline, and at 12, 24, and 36 weeks in the exercise and control groups. A significant group $\times$ time interaction was found for osteocalcin, a bone formation marker, where the marker increased for women in the exercise group $(\mathrm{p}=0.006)$. There were no other significant group $\times$ time interactions for any other marker.

\section{Discussion}

The objective of this study was to evaluate the effects of combined resistance plus aerobic training on body composition and metabolic markers in older breast cancer survivors undergoing AI. Our main finding was that combined training significantly improved the body composition of older breast cancer survivors in the exercise group, mainly through decreased body fat mass, in contrast to increases in the control group. The exercise program did not significantly improve lean mass or bone mineral density. For older breast cancer survivors taking AI, these favorable changes in body composition may be helpful for improving weight management, preventing other obesity-related chronic diseases, and decreasing risk factors for cancer recurrence and metastasis (Brown et al., 2012; Zhu et al., 2016).

Thomas et al. (2016) conducted a similar study with 12 months of aerobic and resistance exercise $(\mathrm{n}=61$, twice-weekly resistance training and $150 \mathrm{~min} /$ week of aerobic) versus usual care in $(\mathrm{n}=60)$ postmenopausal breast cancer survivors taking AI. However, in the present study we supervised the aerobic training while those authors instructed the women to complete $150 \mathrm{~min}$ of moderate-intensity aerobic exercise at home. Although the study found significant improvement in lean mass while we did not, this may be because the current study included 3 months less intervention time. A recent pilot study conducted by De Luca et al. (2016), evaluating the effects of a 
Table 6

Effects of combined training on inflammation, bone and metabolic blood markers in breast cancer survivors.

\begin{tabular}{|c|c|c|c|c|c|c|c|c|c|c|c|c|}
\hline \multirow[t]{2}{*}{ Variables } & \multicolumn{4}{|c|}{ Control group $(n=18)$} & \multicolumn{4}{|c|}{ Exercise group $(\mathrm{n}=18)$} & \multirow[t]{2}{*}{ Time } & \multirow[t]{2}{*}{ Group } & \multirow{2}{*}{$\begin{array}{l}\text { Group } \times \text { time } \\
\text { interaction }\end{array}$} & \multirow[t]{2}{*}{ Effect size } \\
\hline & $\begin{array}{l}\text { Baseline } \\
\text { Mean } \pm \text { SD }\end{array}$ & $\begin{array}{l}12 \text { weeks } \\
\text { Mean } \pm S D\end{array}$ & $\begin{array}{l}24 \text { weeks } \\
\text { Mean } \pm S D\end{array}$ & $\begin{array}{l}36 \text { weeks } \\
\text { Mean } \pm S D\end{array}$ & $\begin{array}{l}\text { Baseline } \\
\text { Mean } \pm S D\end{array}$ & $\begin{array}{l}12 \text { weeks } \\
\text { Mean } \pm S D\end{array}$ & $\begin{array}{l}24 \text { weeks } \\
\text { Mean } \pm S D\end{array}$ & $\begin{array}{l}36 \text { weeks } \\
\text { Mean } \pm S D\end{array}$ & & & & \\
\hline $\begin{array}{l}\text { Cholesterol } \\
\text { (mg/dl) }\end{array}$ & $207 \pm 41$ & $203 \pm 44$ & $213 \pm 42$ & $211 \pm 46$ & $219 \pm 41$ & $213 \pm 33$ & $214 \pm 39$ & $213 \pm 35$ & 0.62 & 0.64 & 0.51 & 0.05 \\
\hline HDL (mg/dl) & $53 \pm 10$ & $52 \pm 9$ & $51 \pm 8$ & $52 \pm 10$ & $55 \pm 10$ & $53 \pm 8$ & $50 \pm 8$ & $51 \pm 8$ & 0.004 & 0.99 & 0.20 & 0.11 \\
\hline LDL (mg/dl) & $131 \pm 36$ & $130 \pm 43$ & $137 \pm 38$ & $137 \pm 42$ & $135 \pm 37$ & $130 \pm 28$ & $126 \pm 35$ & $126 \pm 26$ & 0.79 & 0.70 & 0.06 & 0.31 \\
\hline $\begin{array}{l}\text { No HDL (mg/ } \\
\text { dl) }\end{array}$ & $154 \pm 37$ & $152 \pm 41$ & $160 \pm 38$ & $156 \pm 42$ & $164 \pm 39$ & $159 \pm 30$ & $164 \pm 37$ & $155 \pm 25$ & 0.30 & 0.66 & 0.53 & 0.03 \\
\hline $\begin{array}{l}\text { triglycerides } \\
(\mathrm{mg} / \mathrm{dl})\end{array}$ & $136 \pm 41$ & $141 \pm 47$ & $145 \pm 39$ & $145 \pm 43$ & $148 \pm 68$ & $146 \pm 56$ & $156 \pm 58$ & $147 \pm 55$ & 0.53 & 0.63 & 0.83 & 0.04 \\
\hline $\begin{array}{l}\text { Glucose (mg/ } \\
\text { dl) }\end{array}$ & $110 \pm 22$ & $111 \pm 15$ & $112 \pm 19$ & $108 \pm 19$ & $107 \pm 24$ & $107 \pm 20$ & $103 \pm 20$ & $103 \pm 19$ & 0.24 & 0.42 & 0.41 & 0.26 \\
\hline CRP (mg/dl) & $7 \pm 7$ & $9 \pm 12$ & $6 \pm 6$ & $6 \pm 6$ & $5 \pm 4$ & $6 \pm 6$ & $8 \pm 5$ & $4 \pm 3$ & 0.06 & 0.36 & 0.05 & 0.42 \\
\hline CTX (ng/ml) & $0.40 \pm 0.1$ & $0.33 \pm 0.1$ & $0.33 \pm 0.1$ & $0.33 \pm 0.2$ & $0.46 \pm 0.2$ & $0.48 \pm 0.3$ & $0.47 \pm 0.3$ & $0.46 \pm 0.2$ & 0.21 & 0.11 & 0.09 & 0.65 \\
\hline $\begin{array}{l}\text { Osteocalcin } \\
(\mathrm{ng} / \mathrm{ml})\end{array}$ & $17 \pm 5$ & $17 \pm 6$ & $17 \pm 6$ & $17 \pm 6$ & $19 \pm 8$ & $24 \pm 10^{*, a}$ & $21 \pm 10^{*}$ & $20 \pm 9^{*, \mathrm{~b}}$ & 0.04 & 0.14 & 0.006 & 0.39 \\
\hline
\end{tabular}

Comparative of measurements of inflammation and metabolic blood markers from baseline to nine months of combined training.

* Statistically significant difference between group.

a Bonferroni's post hoc with $\mathrm{p}<0.05$ compared to baseline.

b Bonferroni's post hoc with $\mathrm{p}<0.05$ compared to 12 weeks.

combined aerobic and strength program (24-weeks, 2-times per week, cycle-ergometer pedaling and weight lifting machines) was also consistent with our study outcomes. The authors showed a significant decrease in fat mass percentage $(6.3 \%)$ and improvement in $\mathrm{VO}_{2 \max }$, strength of upper and lower limbs, and quality of life when compared with the control group, and no significant increase in lean mass.

We did not find significant improvement in bone mineral density (hip, spine, and trochanter) and our outcomes are similar to other studies. Knobf et al. (2016) conducted the Yale Fit Trial where the goal was to determine the effects of a 12-month aerobic + resistance exercise intervention on bone mineral density and the biomarker bone turnover in breast cancer survivors. The authors did not find a significant difference in BMD for the exercise vs home-based group, although they found significant BMD loss at all sites (lumbar spine, femoral neck, hip, and trochanter) for subjects on AI. The authors reported that the dose of osteogenic stimulus in the exercise program may have been insufficient for survivors with chemotherapy-induced menopause and for those on adjuvant aromatase inhibitor therapy. Winters-Stone et al. (2011) showed that a controlled trial of 12 months resistance + impact exercise training compared to a stretching group with postmenopausal women preserved BMD at the lumbar spine compared to a loss in controls ( $\mathrm{p}<0.001)$. Results also showed a smaller increase in osteocalcin levels $(p=0.01)$ and a larger decrease in deoxypyridinoline levels $(\mathrm{p}=0.06)$ than controls.

Another trial with pre and postmenopausal breast cancer women, alternating step aerobics and a circuit training program (3-4 times per week - supervised once and home based 2-3 times) and control group, found a decrease in the exercise and control postmenopausal breast cancer groups for lumbar spine and femoral neck BMD. The authors concluded that the exercise intervention improved neuromuscular fitness in both premenopausal and postmenopausal women, although the control group also presented increases in the level of physical activity and this might have contributed to the outcomes (Saarto et al., 2012). However, some studies have shown benefits among premenopausal women but not among postmenopausal women and they suggest that age, lower physical performance, and reduced intensity of training may not impose sufficient stimulus on bone (Sugiyama et al., 2002; Goto et al., 1996). In the present study, the postmenopausal women, $63.2 \pm 7.1$ and $66.6 \pm 9.6$ years of age, did not lose bone mineral density during the program, however we did not find significant differences between groups (exercise and control) for BMD outcomes. This might have occurred as our exercise program had insufficient loading stimulus (without jumping or higher load resistance training), intensity, and length of time to facilitate significant improvements in body mineral density, added to which, importantly, the women were older postmenopausal and used AI.

No favorable effect of combined training was observed for total cholesterol, high and low-density lipoprotein cholesterol, triglycerides, glucose, or CRP. Few randomized intervention trials have assessed the effects of exercise programs on circulating levels of metabolic markers in older breast cancer survivors, but those that have observed no significant improvements for metabolic and inflammatory markers in older breast cancer survivors (Harrigan et al., 2016; Ligibel et al., 2008; Fairey et al., 2005). Bruno et al. (2016) conducted a randomized controlled trial of three months aerobic training on breast cancer survivors and the authors did not find significant improvements for metabolic markers such as glucose $(p=0.51)$, total cholesterol $(p=0.83)$, HDL $(\mathrm{p}=0.80), \quad$ LDL $(\mathrm{p}=0.91)$, triglycerides $(\mathrm{p}=0.73)$, and IGF ( $p=0.62)$. Guinan et al. (2013) showed that aerobic training during eight weeks did not significantly improve body composition, metabolic syndrome markers, CRP, and physical activity in breast cancer.

The strengths of our study include a training program specifically targeted at the multiple side effects of AI for older breast cancer survivors and this the first study to include all body composition compartments and metabolic markers. Although in the present study we conducted 36-weeks of training, the time of intervention may not have been sufficient to improve bone mineral density and metabolic markers. Englund et al. (2009) demonstrated positive effects on bone mineral density only after 12 months of training in older postmenopausal women. Regarding metabolic markers, in accordance with our data, Riesco et al. (2013) compared the lipid profile and inflammatory response in pre and postmenopausal women after 16 weeks aerobic training (three sessions of $45 \mathrm{~min} /$ week at $60 \%$ of heart rate reserve) and although the authors observed a decrease in abdominal subcutaneous adipose tissues they did not find improvement in metabolic markers. On the other hand, Gremeaux et al. (2012) investigated the effects of high-intensity interval exercise and resistance training in overweight and obese individuals (53.3 \pm 9.7 years) during the same period as our study ( 9 months) and demonstrated that lipid profile was significantly improved. Thus, we suggest future studies investigate a longer period of combined training and different intensities of training, such as high-intensity interval exercise plus resistance training on metabolic and bone markers and in older breast cancer survivors undergoing AI. 
Additionally, future studies should control habitual physical activity across time. It is important to highlight that in a preview study performed by our group, Rossi et al. (2017) investigated the changes in total and appendicular body composition, bone mineral density, and metabolic profile following 16 weeks of combined training, and 6 months and 1 year of detraining in healthy postmenopausal women, controlling the change through dietary intake and free-living physical activity using tri-axial accelerometers during the 1 year follow-up to minimize the influence of these variables on the outcomes. They did not observe significant differences in participants' lifestyles during the intervention, or any influence on the body composition and metabolic profile results when they performed adjustments for energy intake and free-living physical activity. In the present study, although we did not verify significant changes in dietary intake and no differences were observed in metabolic and body composition markers when adjusted by food intake, it is necessary to verify the habitual physical activity behavior in older breast cancer survivors undergoing AI.

Our exercise program demonstrated high compliance and the results suggest that combined aerobic + resistance exercise is able to improve body composition, such as preventing fat gain in older breast cancer survivors undergoing AI. Our findings suggest that a longer combined exercise program and/or more loading in the resistance exercise and high intensity during the aerobic training protocol may have beneficial effects on improving metabolic markers and bone mineral density in older breast cancer survivors undergoing aromatase inhibitor therapy. All these outcomes can help, and should be taken in account, when planning future exercise intervention studies. In addition, a combined program can be used to decrease the side effects of cancer treatment, as a facilitative strategy to promote health and quality of life in older breast cancer survivors.

\section{Conflicts of interest}

The authors declare that they have no conflict of interest.

\section{Acknowledgements}

The Amazon Research Foundation - FAPEAM, supported Scholarship.

\section{References}

Adams, G.M., 1994. Exercise Physiology: Laboratory Manual, 2nd ed. Brown and Benchmark Publishers, Dubuque, Iowa.

Akyol, M., Demir, L., Alacacioglu, A., et al., 2016. The effects of adjuvant endocrine treatment on serum leptin, serum adiponectin and body composition in patients with breast cancer: the Izmir Oncology Group (IZOG) study. Chemotherapy 61, 57-64.

Almstedt, H.C., Grote, S., Korte, J.R., Beaudion, S.P., Shoepe, T.C., Strand, S., Tarleton, H.P., 2016. Combined aerobic and resistance training improves bone health of female cancer survivors. Bone Rep. 5, 274-279.

Alshurafa, M., Briel, M., Akl, E.A., et al., 2012. Inconsistent definitions for intention-totreat in relation to missing outcome data: systematic review of the methods literature. PLoS One. https://doi.org/10.1371/journal.pone.0049163.

Amir, E., Seruga, B., Niraula, S., et al., 2011. Toxicity of adjuvant endocrine therapy in postmenopausal breast cancer patients: a systematic review and meta-analysis. J. Natl. Cancer Inst. 103, 1299-1309.

Bardia, A., Arieas, E.T., Zhang, Z., et al., 2012. Comparison of breast cancer recurrence risk and cardiovascular disease incidence risk among postmenopausal women with breast cancer. Breast Cancer Res. Treat. 131, 907-914.

Battaglini, C.L., Mills, R.C., Phillips, B.L., et al., 2014. Twenty-five years of research on the effects of exercise training in breast cancer survivors: a systematic review of the literature. World J. Clin. Oncol. 5 (2), 177-190.

Battisti, S., Guida, F.M., Coppa, F., et al., 2014. Modification of abdominal fat distribution after aromatase inhibitor therapy in breast cancer patients visualized using 3-D computed tomography volumetry. Clin. Breast Cancer 14, 365-370.

Brown, J.C., Winters-Stone, K., Lee, L., et al., 2012. Cancer, physical activity, and exercise. Compr. Physiol. 2 (4), 2775-2809.

Bruno, E., Roveda EE, E., Vitale, J., et al., 2016. Effect of aerobic exercise intervention on markers of insulin resistance in breast cancer women. Eur. J. Cancer Care 1-9.

Cohen, J., 1988. Statistical Power Analysis for the Behavioral Sciences, 2. Auflage. Erlbaum, Hillsdale, NJ.

De Luca, V., Minganti, C., Borrione, P., et al., 2016. Effects of concurrent aerobic and strength training on breast cancer survivors: a pilot study. Public Health 136,
$126-132$.

Dieli-Conwright, C.M., Orozco, B.Z., 2015. Exercise after breast cancer treatment: current perspectives. Breast Cancer Targets Ther. 7, 353-362.

Ebbeling, C., Ward, A., Puleo, E., Widrick, J., Rippe, J., 1991. Development of a singlestage submaximal treadmill walking test. Med. Sci. Sports Exerc. 23, 966-973.

Englund, U., Littbrand, H., Sondell, A., et al., 2009. The beneficial effects of exercise on BMD are lost after cessation: a 5-year follow-up in older post-menopausal women. Scand. J. Med. Sci. Sports 19 (3), 381-388.

Fairey, A.S., Courneya, K.S., Field, C.J., et al., 2005. Effect of exercise training on Creactive protein in postmenopausal breast cancer survivors: a randomized controlled trial. Brain Behav. Immun. 19, 381-388.

Ferlay, J., Shin, H.R., Bray, F., et al., 2010. Estimates of worldwide burden of cancer in 2008: GLOBOCAN 2008. Int. J. Cancer 127, 2893-2917.

Foglietta, J., Inno, A., Iuliis, F., et al., 2017. Cardiotoxicity of aromatase inhibitors in breast cancer patients. Clin. Breast Cancer 17, 11-17.

Friedenreich, C.M., Neilson, H.K., Woolcott, C.G., et al., 2012. Inflammatory marker changes in a yearlong randomized exercise intervention trial among postmenopausal women. Cancer Prev. Res. 5 (1), 98-108.

Goto, S., Shigeta, H., Hyakutake, S., et al., 1996. Comparison between menopause-related changes in bone mineral density of the lumbar spine and the proximal femur in Japanese female athletes: a long-term longitudinal study using dual-energy X-Ray absorptiometry. Calcif. Tissue Int. 59, 461-465.

Gremeaux, V., Drigny, J., Nigam, A., et al., 2012. Long-term lifestyle intervention with optimized high-intensity interval training improves body composition, cardiometabolic risk, and exercise parameters in patients with abdominal obesity. Am. J. Phys. Med. Rehabil. 91 (11), 941-950.

Guinan, E., Hussey, J., Broderick, J.M., et al., 2013. The effect of aerobic exercise on metabolic and inflammatory markers in breast cancer survivors - a pilot study. Support Care Cancer 21, 1983-1992.

Harrigan, M., Cartmel, B., Erikka Loftfield, E., et al., 2016. Randomized trial comparing telephone versus in-person weight loss counseling on body composition and circulating biomarkers in women treated for breast cancer: the Lifestyle, Exercise, and Nutrition (LEAN) study. J. Clin. Oncol. 34 (7), 669-676.

Human, R.P., Jones, G.A., 2004. Evaluation of swab transport systems against a published standard. J. Clin. Pathol. 57, 762-763.

Instituto Nacional do Câncer (INCA), 2016. Estimativa 2016: Incidência de Câncer no Brasil/Instituto Nacional de Câncer José Alencar Gomes da Silva, Coordenação de Prevenção e Vigilância. (Rio de Janeiro).

International Agency for Research on Cancer, 2012. GLOBOCAN 2012: Estimated Cancer Incidence, Mortality and Prevalence Worldwide in 2012. pp. 3030-3044.

Kanis, J.A., Mccloskey, E.V., Johansson, H., et al., 2013. European guidance for the diagnosis and management of osteoporosis in postmenopausal women. Osteoporos. Int. 24, 23-57.

Knobf, M.T., Jeon, S., Smith, B., 2016. Effect of a randomized controlled exercise trial on bone outcomes: influence of adjuvant endocrine therapy. Breast Cancer Res. Treat. 155, 491-500.

Ligibel, J.A., Campbell, N., Partridge, A., et al., 2008. Impact of a mixed strength and endurance exercise intervention on insulin levels in breast cancer survivors. J. Clin. Oncol. 26 (6), 907-912.

Limburg, C.E., 2007. Screening, prevention, detection, and treatment of cancer therapy induced bone loss in patients with breast cancer. Oncol. Nurs. Forum 34, 55-63.

Napoli, N., Rastelli, A., Ma, C., Colleluori, G., Vattikuti, S., Armamento-Villareal, R. 2015. Genetic polymorphism at Val80 (rs700518) of the CYP19A1 gene is associated with body composition changes in women on aromatase inhibitors for ER (1) breast cancer. Pharmacogenet. Genomics 25, 377-381.

National Center for Health Statistics, 2016. Health, United States, 2015: With Special Feature on Racial and Ethnic Health Disparities. (Hyattsville, MD).

Paulo, T.R.S., Winters-Stone, K.M., Viezel, J., Rossi, F.E., Aro, B.L., Trindade, A.C.C., Codogno, J.S., Freitas Junior, I.F., 2018. Comparing exercise responses to aerobic plus resistance training between postmenopausal breast cancer survivors undergoing aromatase inhibitor therapy and healthy women. Disabil. Rehabil. https://doi.org/ $10.1080 / 09638288.2018 .1460877$.

Peppone, L.J., Mustian, K.M., Janelsins, M.C., et al., 2010. Effects of a structured weight bearing exercise program on bone metabolism among breast cancer survivors: a feasibility trial. Clin. Breast Cancer 10, 224-229.

Riemsma, R., Forbes, C.A., Kessels, A., et al., 2010. Systematic review of aromatase inhibitors in the first-line treatment for hormone sensitive advanced or metastatic breast cancer. Breast Cancer Res. Treat. 123, 9-24.

Riesco, E., Tessier, S., Lacaille, M., et al., 2013. Impact of a moderate-intensity walking program on cardiometabolic risk markers in overweight to obese women: is there any influence of menopause? Menopause 20 (2), 185-193.

Rossi, F.E., Diniz, T.A., Neves, L.M., et al., 2017. The beneficial effects of aerobic and concurrent training on metabolic profile and body composition after detraining: a 1 year follow-up in postmenopausal women. Eur. J. Clin. Nutr. 71 (5), 638.

Saarto, T., Vehmanen, L., Blomqvist, C., et al., 2008. Ten-year follow-up of 3 years of oral adjuvant clodronate therapy shows significant prevention of osteoporosis in earlystage breast cancer. J. Clin. Oncol. 26, 4289-4295.

Saarto, T., Sievänen, H., Kellokumpu-Lehtinen, P., et al., 2012. Effect of supervised and home exercise training on bone mineral density among breast cancer patients. A 12 month randomised controlled trial. Osteoporos. Int. 23 (5), 1601-1612.

Sugiyama, T., Yamaguchi, A., Kawai, S., 2002. Effects of skeletal loading on bone mass and compensation mechanism in bone: a new insight into the "mechanostat" theory. J. Bone Miner. Metab. 20, 196-200.

Thomas, G.A., Cartmel, B., Harrigan, M., et al., 2016. The effect of exercise on body composition and bone mineral density in breast cancer survivors taking aromatase inhibitors. Obesity 25 (2), 346-351. 
Van Londen, G.J., Perera, S., Vujevich, K., et al., 2011. The impact of an aromatase inhibitor on body composition and gonadal hormone levels in women with breast cancer. Breast Cancer Res. Treat. 125, 441-446.

Winters-Stone, K.M., Dobek, J., Nail, L., et al., 2011. Strength training stops bone loss and builds muscle in postmenopausal breast cancer survivors: a randomized, controlled trial. Breast Cancer Res. Treat. 127 (2), 447-456.

Zhu, G., Zhang, X., Wang, Y., et al., 2016. Effects of exercise intervention in breast cance survivors: a meta-analysis of 33 randomized controlled trails. OncoTargets Ther. 9, 2153-2168. 